\title{
Efficacy of a low dose fipronil bait against blacklegged tick (Ixodes scapularis) larvae feeding on white-footed mice (Peromyscus leucopus) under laboratory conditions
}

David M. Poché*, Gregory Franckowiak, Tyler Clarke, Batchimeg Tseveenjav, Larisa Polyakova and Richard M. Poché

\begin{abstract}
Background: Lyme disease is the most prevalent vector-borne disease in the USA with cases continuing to increase. Current control measures have not been shown to be impactful, and therefore alternatives are needed. Treating pathogen reservoirs with low dose systemic acaricides in endemic areas may provide a useful tool for disrupting the cycle of the vector and pathogen. The purpose of this study was to determine the efficacy of a $0.005 \%$ fipronil bait, presented orally to white-footed mice, in controlling blacklegged tick larvae (larvae).

Methods: Sixty mice were assigned to 3 treatment groups and three untreated control groups. All individually housed mice in treatment groups were exposed to $0.005 \%$ fipronil bait for 48 hours. Larvae were manually applied to mice within feeding capsules at one of three timepoints: Day 1, Day 9 and Day 15 post-exposure. For 4-days posttick attachment, replete larvae were collected from water moats underneath each cage and attached larvae were observed by microscopy. Plasma from 4 treated mice at Day-1, Day 13 and Day 19 , and 4 control mice $(n=16)$ was collected to obtain fipronil plasma concentrations (CP).
\end{abstract}

Results: Fipronil bait did not appear to produce neophobia in mice, as the amount of bait eaten at 24- and 48-hours exposure did not differ significantly. The 48-hour fipronil bait exposure prevented $100 \%$ of larvae from feeding to repletion at Day 1, Day 9 and Day 15 post-treatment. Within the treatment groups, all larvae observable within the capsules expired and were prevented from detaching by Day 4. In contrast, within the control groups a total of 502 replete larvae were collected from moats and 348 larvae observable within the capsules successfully detached. CP averaged 948.9, 101.2 and $79.4 \mathrm{ng} / \mathrm{ml}$ for mice euthanized at Day 1, Day 9 and Day 15, respectively. No fipronil was detected in control mice.

Conclusions: We provide early indication that low dose fipronil bait, orally presented to white-footed mice, can effectively control blacklegged tick larvae. Future research should modify the exposure duration and post-exposure tick attachment timepoints to simulate various field scenarios under which successful efficacy might be obtained. Low dose fipronil bait could provide a cost-effective, practical means of controlling blacklegged ticks and other arthropod vectors.

Keywords: Borrelia burgdorferi (sensu stricto), Blacklegged ticks, Ixodes scapularis, White-footed mice, Peromyscus leucopus, Fipronil bait, Acaricides, Systemic insecticides, Vector control adaptation, distribution and reproduction in any medium or format, as long as you give appropriate credit to the original author(s) and the source, provide a link to the Creative Commons licence, and indicate if changes were made. The images or other third party material in this article are included in the article's Creative Commons licence, unless indicated otherwise in a credit line to the material. If material is not included in the article's Creative Commons licence and your intended use is not permitted by statutory regulation or exceeds the permitted use, you will need to obtain permission directly from the copyright holder. To view a copy of this licence, visit http://creativeco mmons.org/licenses/by/4.0/. The Creative Commons Public Domain Dedication waiver (http://creativecommons.org/publicdomain/ zero/1.0/) applies to the data made available in this article, unless otherwise stated in a credit line to the data. 


\section{Background}

Lyme disease is the most prevalent vector-borne disease transmissible to man in the USA and cases have continued to increase from 2001 to present $[1,2]$, with over 300,000 cases estimated to occur annually and a geographical distribution that is continually expanding $[2,3]$. In the USA, human instances of Lyme disease are most commonly reported in the midwestern/ north-central and northeastern regions $[1,4]$ where the blacklegged tick (Ixodes scapularis) serves as the primary pathogen vector for the Lyme disease spirochete (Borrelia burgdorferi (sensu stricto)) with the white footed mouse (Peromsyscus leucopus) serving as a primary reservoir host for immature blacklegged ticks in these regions [5].

Initial Lyme disease symptoms are flu-like and accompanied by a specific rash present in $60-80 \%$ of patients referred to as erythema migrans [6]. If cases are not quickly treated with antibiotics, infection can spread to joints, the heart, and nervous system [4]. Lyme disease is difficult to diagnose, partly because of clinical non-specificity [7], and it is not uncommon for patients treated with 2-4 weeks of antibiotics to suffer from post-treatment Lyme disease syndrome (PTLDS) which can last for more than six months and may last for many years [8]. The economic burden of Lyme disease is substantial with the cost to the American Healthcare System having been estimated to be between $\$ 712$ million and $\$ 1.3$ billion per year, and annual fees per patient suffering from PostTreatment Lyme Disease Syndrome (PTLDS) are estimated to be $\$ 3000$ and $\$ 3800$ [9]. Thus, the disease is still of understandable importance in the USA and alternative methods of disease prevention and vector control should continue to be investigated to alleviate the significant burden placed upon medical practitioners and patients.

Acaricide application methods aimed at controlling blacklegged ticks are among the more promising approaches for Lyme disease prevention. However, largescale pesticide application has been hindered largely as a biproduct of environmental concerns [10, 11]. Traditional methods such as dusting or blanket spraying require a large volume of acaricide and a high concentration of active ingredient in the formulations [11] that are exponentially higher than what would be required to control tick larvae and nymphs [12-14]. The greatest risk factors for Lyme disease are exposure to infected Ixodes spp. ticks and reservoir host animals, particularly the white-footed mouse, in woody, grassy areas [15].

The life-cycle of blacklegged ticks takes approximately two years to complete and is composed of four life stages (eggs, larvae, nymphs and adults). After the eggs hatch, they require a blood meal at each subsequent life stage to survive and develop [16]. Larvae hatch pathogen-free in the summer and take a blood meal from small rodents, host-feeding heavily on white-footed mice. It is at this point that they acquire the B. burgdorferi (s.s.) spirochete. Once larvae have blood-fed to repletion, they detach from the host and begin molting. Infected larvae will typically emerge to feed as nymphs the following spring. The risk of human exposure to Lyme disease is shown to be a function of the local abundance of nymphal and adult ticks [17] and is strongly correlated with the density of spirochete-infected ticks in the areas surrounding residences [18]. Nymphs are believed to be the primary pathogen reservoir responsible for $B$. burdorferi transmission [2] and may be responsible for as much as $90 \%$ of Lyme disease cases each year [19]. Risk of B. burgdorferi (s.s.) infection is shown to increase in response to increases in infected nymphs [20]. Given the issues regarding traditional acaricide application and B. burgdorferi (s.s.) risk factors such as density of nymphs and proximity of host animals, strategies such as targeting white-footed mice with an acaricide, aimed at reducing larval tick density, could prove beneficial. A targeted approach would markedly reduce the amount of active ingredient being applied in the field, which would pose a reduced risk to non-target organisms. Significantly reducing larvae feeding on white-footed mice could reduce the density of incoming nymphs and reduce B. burgdorferi (s.s.) infection rates.

Fipronil is a phenylpyrozol that interferes with arthropod central nervous systems by blocking the GABAgated and glutamate-gated chloride channels [21]. It has shown promise in controlling several arthropod pests and has been explored for use in tick control. One such method being explored is the use of the Select TCS bait box (EPA Est. No. 85306-CT-001). This approach involves a bait station, which is filled with attractive bait and is fitted with a cotton or felt wick treated with a concentration of $0.70-0.75 \%$ fipronil that is topically applied to white-footed mice entering the bait station [22-24]. While the approach has reduced ticks under experimental conditions, its deficiencies have hindered widespread use. The bait station is noted as being costly and needing to be periodically replaced [24]. Mice are also able to avoid the wick or will routinely remove them for use as bedding material [23]. Thus, many mice entering the bait stations to feed are not inoculated and use of a single wick with fipronil requires bait stations be replaced. Additionally, the product is a restricted use pesticide, meaning that only licensed pest control professionals may use it, which further limits utilization. Bait stations/boxes will need to be baited regardless of the route of acaricide administration (i.e. topical, oral). Thus, a practical and cost-effective solution would be to load the bait stations with a low dose acaricide bait for oral uptake by white-footed mice. 
An oral acaricide bait would act systemically, meaning the acaricide would be absorbed by larvae during blood-feeding. Under field conditions, this approach could disrupt the B. burgdorferi (s.s.) cycle by preventing blacklegged tick larvae from feeding to repletion and detaching, subsequently reducing the number of nymphs that humans would typically be exposed to. During previous laboratory research, fipronil baits, at concentrations of $0.097 \%$ and $0.0485 \%$, presented orally to house mice (Mus musculus) were $100 \%$ efficacious in preventing larval blacklegged ticks from feeding to repletion when larvae were fed on mice immediately following a 48-hour exposure period [25]. A more recent laboratory study evaluated the use of $0.005 \%$ and $0.0015 \%$ fluralaner baits presented orally to deer mice (Peromyscus maniculatus) [26]. When mice were exposed to these baits for 24 hours, at Day-2 post-exposure, blacklegged tick larvae were reduced by up to $97 \%$ and $94 \%$, respectively.

The results of these above studies are useful; however, additional research is warranted. The above studies utilized house mice [25] and deer mice [26], respectively. While these studies provide insights regarding the potential for blacklegged tick control, additional mammalian species should be investigated, particularly the whitefooted mouse. Additional mammalian reservoirs such as chipmunks and shrews may be significant hosts for immature ticks and may be pathogen reservoirs in certain locations, a belief speculated to have contributed to the failure of some white-footed mouse treatment schemes [27]. However, given the fact that the whitefooted mouse is a well-established primary pathogen reservoir in the midwestern and northeastern USA, and the fact that fipronil-based treatments targeting white-footed mice have shown promise in controlling ticks in both laboratory and field settings, we would argue that it is currently the most appropriate rodent model for assessing the potential for a low dose fipronil bait to control immature blacklegged ticks in the northeastern and midwestern USA.

Additionally, the ticks attached to mice during these studies were allowed to free-feed on mice, making direct tick observation difficult. Oral acaricides act systemically, causing ticks to expire during blood-feeding and many remain attached to the host. Feeding capsules have become a standard in tick colonies to facilitate bloodfeeding and promote development and oviposition [2831 ] and could provide a useful method for observing and confirming the mortality of attaching ticks. The use of a capsule may also prevent ticks from being removed and damaged during grooming, an issue previously reported by other researchers $[26,32]$.

The above oral acaricide baits were efficacious in controlling blacklegged tick larvae. However, palatability was noted to be an issue with the fipronil baits [25]. The concentrations in these baits were $0.097 \%$ and $0.0485 \%$, which were much higher than necessary to control ticks and may have contributed to taste aversion. More recent field experiments involving fleas suggest that the fipronil concentration in these baits could be reduced markedly. In Northern Colorado, application of a $0.005 \%$ fipronil bait resulted in $>95 \%$ control of Oropsylla spp. fleas infesting blacktailed prairie dogs up to 52 days post-fipronil bait application [33]. During another field trial in southeastern Kazakhstan, 0.005\% fipronil bait application resulted in $100 \%$ removal of Xenopsylla spp. fleas infesting great gerbils (Rhombomys opimus) up to 80-days post-fipronil bait application [34]. Additional laboratory bioassays have indicated $0.005 \%$ fipronil to effectively control adult and larval phlebotomine sand flies (Phlebotomus argentipes) [35]. The effectiveness of low dose fipronil baits against fleas and phlebotomine sand flies infesting rodents suggest that the potential to control blacklegged ticks should be evaluated. The nominal concentration in $0.005 \%$ fipronil baits is roughly $19.4 \times$ and $9.7 \times$ lower than that of the fipronil baits previously utilized in tick control [25], which would pose reduced risk to white-footed mice and non-target organisms. If properly evaluated, a $0.005 \%$ oral fipronil bait could prove to be a useful addition to integrated tick management programs.

The study conducted by Pelletier et al. [26] estimated efficacy two days after tick attachment, only. Larvae feed for $\sim 4$ days after which replete larvae will drop off and begin molting [36]. Therefore, ticks not succumbing to acaricides at Day-2 post-tick attachment may still expire prior to feeding to repletion and detaching. It would be useful to evaluate the efficacy of acaricides over a duration spanning the $\sim 4$-day larval tick attachment period.

The purpose of this laboratory study was to determine the efficacy of an oral acaricide, paraffin rodent bait containing $0.005 \%$ fipronil, presented to white-footed mice for 48 hours, in controlling larval blacklegged ticks allowed to attach to mice at Day 1, Day 9 and Day 15 post-bait exposure. We hypothesized that fipronil bait would successfully control blacklegged tick larvae by preventing them from feeding to repletion and detaching, and subsequently preventing molting and nymph development (Fig. 1). We estimated the effectiveness of the bait by collecting blacklegged tick larvae which fed to repletion and detached up to 4 days post-tick attachment and by observing larvae attached to the host via microscopy. Our target efficacy was a minimum of $90 \%$ success in preventing larvae from feeding to repletion and detaching, relative to control groups, following the guidelines of the United States 


\section{a Vector-host association \\ Pathogen Reservoir: Peromyscus leucopus}

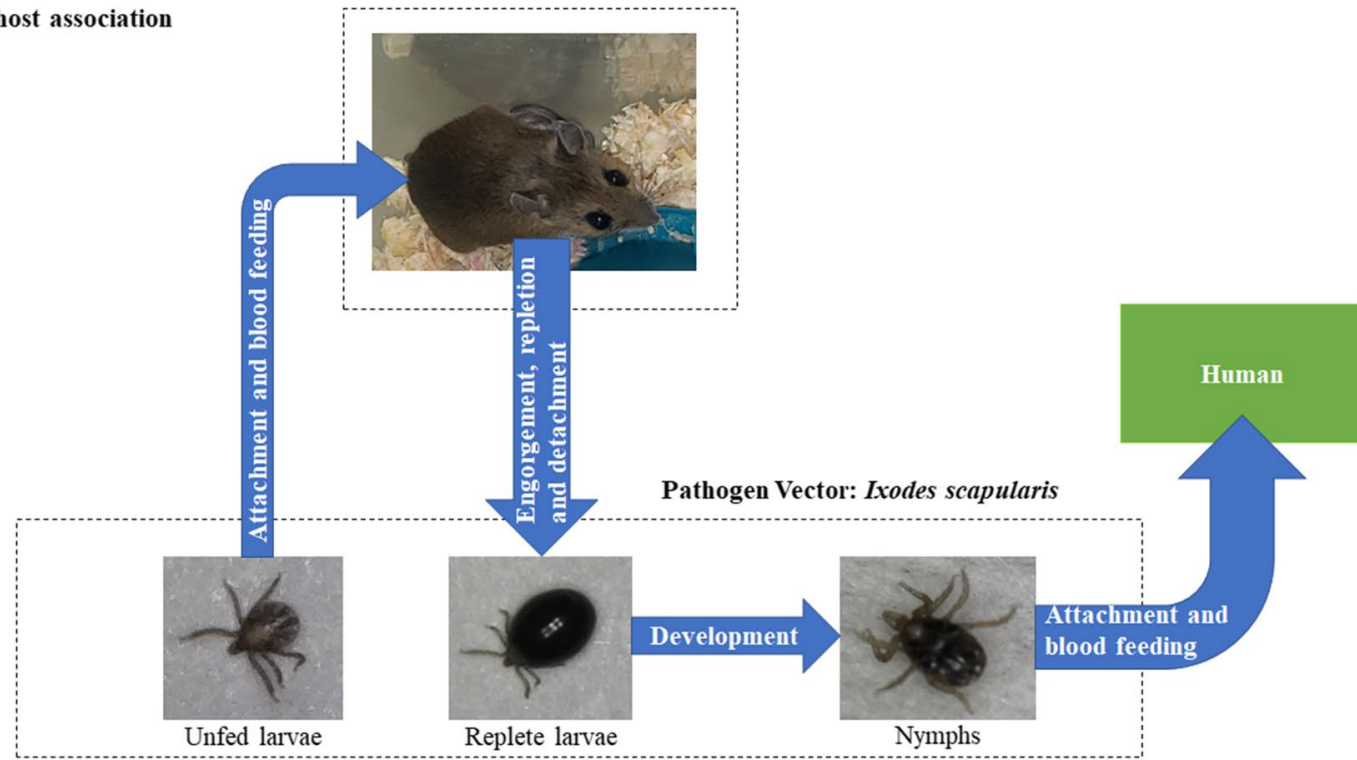

\section{b Impact of targeted control}

Pathogen Reservoir: Peromyscus leucopus

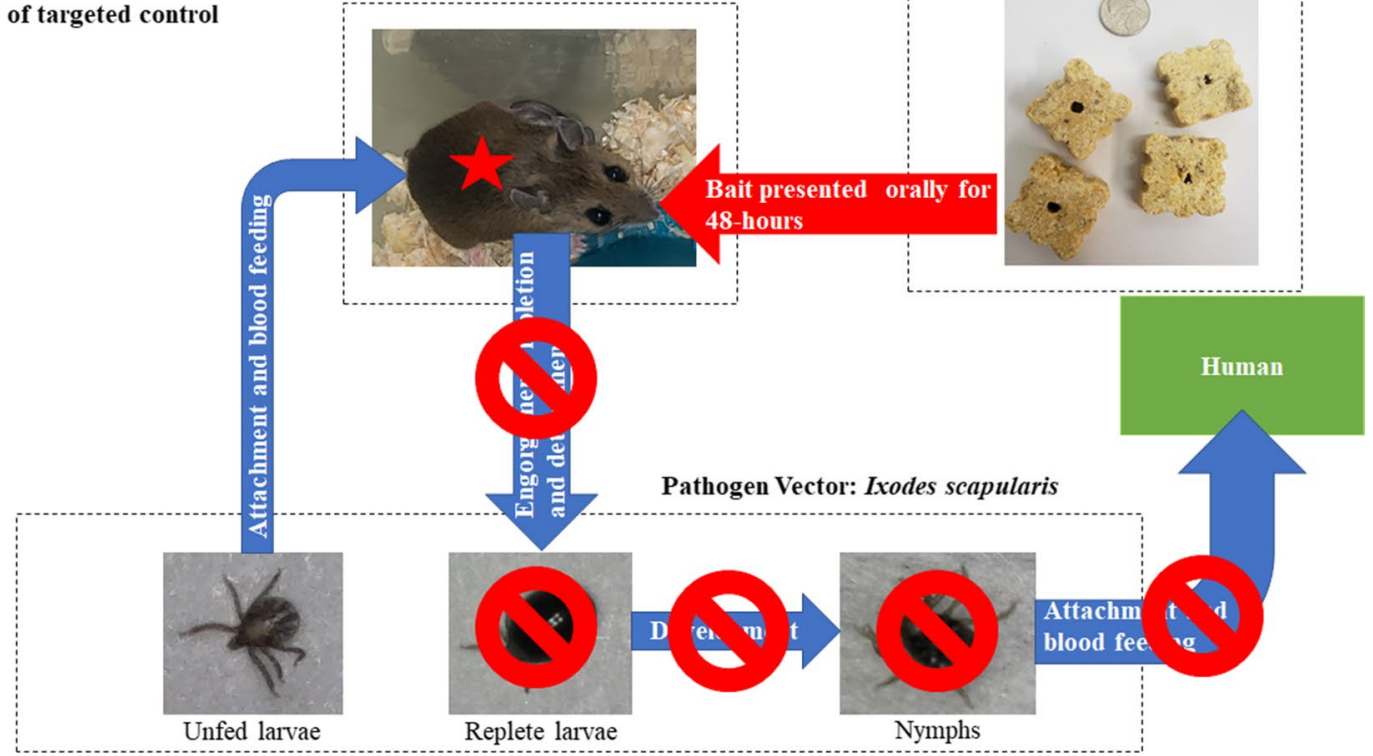

Fig. 1 a Vector-host association: Larvae attach to the white-footed mouse and begin blood-feeding for $~ 4$ days. Fully engorged, replete larvae drop from the host and begin nymph development. Infected nymphs can then bite humans. b The impact of fipronil bait consumption by white-footed mice on development of blood-feeding larvae: Larvae blood-feeding on mice that consume fipronil bait expire and are prevented from feeding to repletion and detaching, subsequently preventing nymph development and reducing the risk of human nymph bites

Environmental Protection Agency (EPA) who require a minimum efficacy of at least $90 \%$ against ectoparasites [37].

\section{Methods}

This research was performed under laboratory conditions at Genesis Laboratories, Inc. (Genesis) in Wellington, Colorado. 


\section{White-footed mice}

All procedures performed during this study involving white-footed mice, and the test protocol, were approved by the Genesis Institutional Animal Care and Use Committee (IACUC) (March 18, 2019) and followed AWA and Genesis IACUC policies (Study No. 19001).

Test mice were from an outbred white-footed mouse breeding colony originally initiated using 20 mice received from the Peromyscus Genetic Stock Center (University of South Carolina). Mice were housed separately in order to accurately estimate individual consumption and to reduce the probability of mice removing attached ticks. Mice were housed in screen-bottom metal cages with a surface area of $\sim 550 \mathrm{~cm}^{2}$ in accordance with EPA recommendations [38].

\section{Blacklegged ticks}

Blacklegged tick larvae (larvae) feed heavily on whitefooted mice, which are a key pathogen reservoir. Larvae were acquired from the Oklahoma State Tick Rearing Facility (Stillwater, OK, USA) and were maintained in a regulated insectary. Temperatures in the insectary were maintained at $\sim 20-24{ }^{\circ} \mathrm{C}$ with a photoperiod of 12 hours light:12 hours dark. Larvae were housed in a rearing desiccator, with temperature and relative humidity maintained at $\sim 21-22{ }^{\circ} \mathrm{C}$ and $>90-99 \%$, respectively. A saturated solution of potassium sulfate (140 g/l water) was added to the desiccator to maintain humidity and prevent mold growth. Humidity and temperature were monitored daily.

\section{Fipronil bait}

The fipronil bait was manufactured as a solid bait block containing a nominal concentration of $0.005 \%$ fipronil $(50 \mathrm{mg} / \mathrm{kg}$ ) (Scimetrics Limited Corp., Wellington, Colorado). The bait formulation consisted largely of paraffin wax and was of limited nutritional value. Before presenting fipronil bait to mice, the nominal fipronil concentration $(0.005 \% ; 50 \mathrm{mg} / \mathrm{kg})$ was confirmed by separating matrix interferences using a validated method of high-performance liquid chromatography (HPLC) and ultraviolet (UV) detection. The mean fipronil concentration was $47.8 \pm 4.65 \mathrm{mg} / \mathrm{kg}$ (CV: 9.73\%; Recovery: 95.6\%). The bait was within the requirements outlined by the EPA for test substance concentration $( \pm 10 \%)$.

\section{Experimental design}

\section{Pre-exposure (Acclimation)}

Sixty mice were individually housed and acclimated to test conditions for 7 days prior to fipronil bait exposure. During acclimation, mice were observed daily for general health and were provided fresh water and commercial laboratory rodent diet ad libitum. A veterinarian inspected the mice prior to fipronil bait exposure to ensure that all were suitable for the study.

\section{Group assignment}

The sex, weight, and parental lineage of mice were indicators used to randomly assign them to test groups using a sequence generator (random.org). Each group was assigned 5 males and 5 females. Test group mice were distinguished by (i) exposure to fipronil bait (Yes/No); and (ii) the timepoint post-exposure during which larvae were allowed to attach and feed (Table 1).

\section{Exposure}

At the end of acclimation, commercial rodent diet was removed from the cages of each mouse within TDay1, TDay 9 and TDay15 and replaced with $\sim 20 \mathrm{~g}$ fipronil bait. Mice were provided the fipronil bait exclusively for 48-h. A multi-day exposure period was selected to address the neophobic behavior displayed by animals presented with novel stimuli [39], with the assumption that more than 24-h exposure would increase the probability of fipronil bait being consumed. Hence, consumption would be greater on Day 2 exposure relative to Day 1. Fipronil bait was weighed to the nearest $0.1 \mathrm{~g}$ daily. Mice within the control groups (CDay1, CDay9, CDay15) received no fipronil bait and were presented with commercial rodent diet which was replenished ad libitum.

\section{Post-exposure}

At the conclusion of the exposure period, all remaining fipronil bait was removed and replaced with commercial rodent diet provided ad libitum for the remainder of the experiment. Mice were observed daily for health. During post-exposure, mice within test groups were exposed to larvae at one of three timepoints. This process is described explicitly below.

\begin{tabular}{llll}
$\begin{array}{l}\text { Table } \mathbf{1} \text { The } \\
\text { timepoints }\end{array}$ & six test & groups utilized and the attachment \\
\hline Test group ID* & \multicolumn{4}{l}{ No. of mice with larvae attached } \\
\cline { 2 - 4 } & \multicolumn{2}{l}{ Timepoint post-exposure } \\
\cline { 2 - 4 } & Day 1 & Day 9 & Day 15 \\
\hline Treatment Day 1 & 10 & - & - \\
Treatment Day 9 & - & 10 & - \\
Treatment Day 15 & - & - & 10 \\
Control Day 1 & 10 & - & - \\
Control Day 9 & - & 10 & - \\
Control Day 15 & - & - & 10 \\
\hline
\end{tabular}




\section{Tick attachment}

Mice within the test groups, were assigned to one of three tick attachment timepoints: Day 1 (TDay1, CDay1); Day 9 (TDay9, CDay9); and Day 15 (TDay15, CDay15) post-exposure.

During tick attachment, larvae were applied to each mouse within a small feeding capsule made using $\sim^{1 / 4}$ of a $1.5 \mathrm{ml}$ plastic centrifuge tube. The capsules were used to (i) focus larval feeding in an isolated area to allow for direct observation; and (ii) improve larvae recovery by preventing mice from removing them through grooming. Capsules are a preferred method of containing and localizing ticks when facilitating blood-feeding [28-31]. Approximately 40 larvae were applied to each capsule to increase the probability of successful feeding and larvae recovery.

Mice were individually placed into an induction chamber and anesthetized using an isoflurane vaporizer. The vaporizer was set to $4 \%$ isoflurane with an oxygen flow rate of $2 \mathrm{l} / \mathrm{min}$. Once each mouse was anesthetized, it was removed from the induction chamber and attached to a nosecone (Fig. 2). The vaporizer and oxygen flow rate were then reduced to $1.5-2.0 \%$ and $0.5 \mathrm{l} / \mathrm{min}$, respectively. Mice were monitored throughout the procedure to ensure that they were breathing normally.

A patch of fur between each anesthetized mouse's shoulder blades was carefully trimmed to near the skin using an Equine $\mathrm{FX}^{\mathrm{TM}}$ horse shearer (Conair Corp., Stamford, CT, USA). This was done to improve the ability to observe attached larvae during blood-feeding. The capsule was attached using a mixture of rosin and natural bees wax (3:1 ratio). The mixture was heated using a hot plate (IKA ${ }^{\circledR}$ C-Mag HS 7) until it was malleable enough to apply to the mice and was then allowed to cool for $\sim 3$ min. The mixture was applied to the rim of the capsule which was then secured to the shaved area of the mouse. This method is used routinely to blood-feed ticks in laboratory settings and did not significantly impact the behavior or longevity of ticks during this study.

While attaching larvae, the work surface was covered with a layer of white paper so that escaped larvae would be detectable. Double-sided tape was applied to the perimeter of each work surface, the base of each wall, and the perimeter of the doorway to prevent larvae from
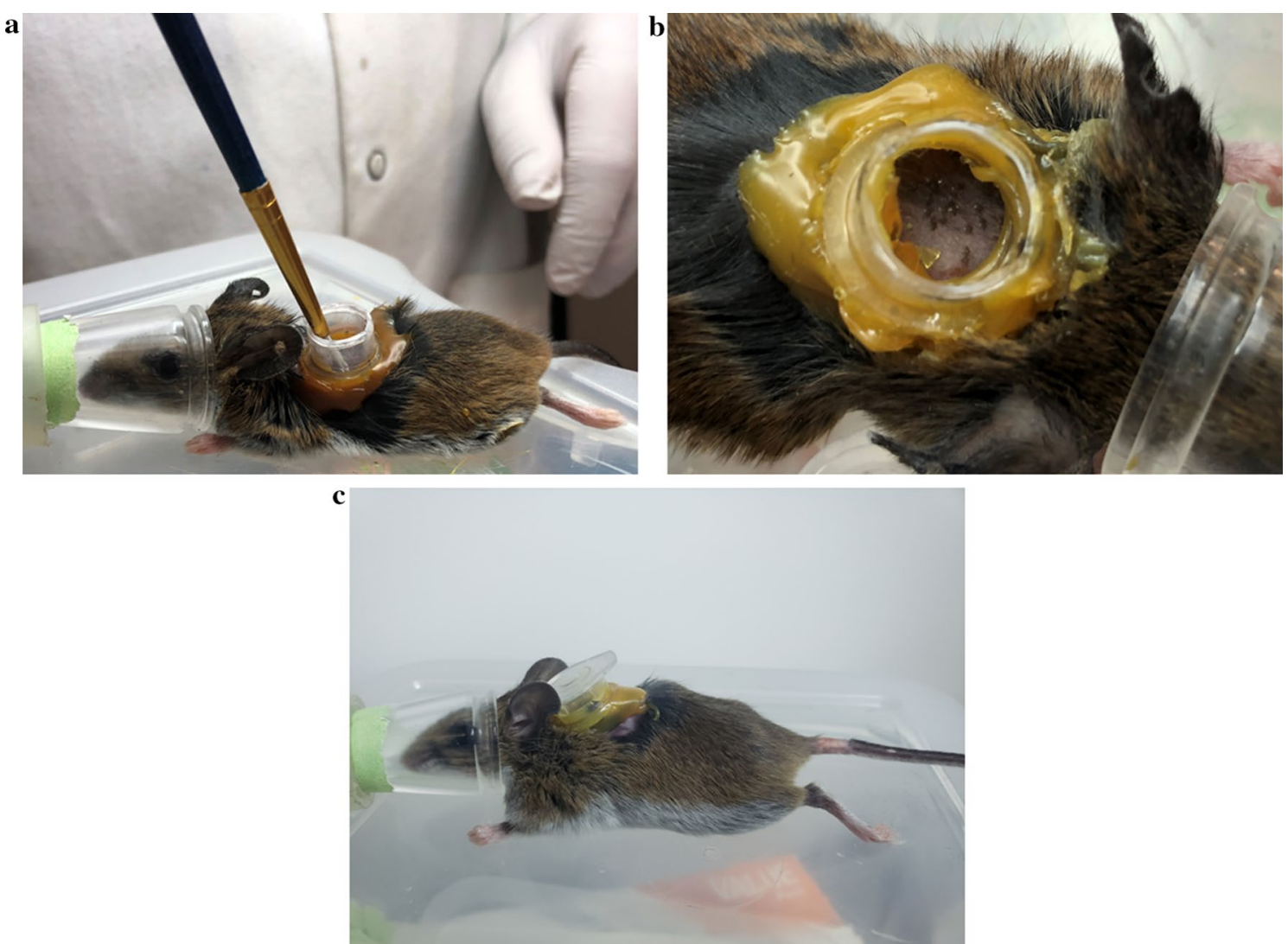

Fig. 2 Mouse connected to the isoflurane nosecone. a Larvae being applied via fine-tipped paint brush. b Larvae within capsule. c Completed capsule with lid secured 
escaping the insectary. Tubes containing larval masses were placed into a white plastic tub lined with petroleum jelly to prevent escape. Active larvae displaying questing activity were selected from two larval masses. Forty larvae were transferred into each capsule using a fine-tipped paint brush (Fig. 2a, b). A plastic lid punctured with holes was secured to each capsule opening (Fig. 2c). The lids provided adequate air exchange while preventing larvae from escaping through the capsule opening. After completion of capsule and tick attachment, mice were removed from the nosecone and returned to their respective cages and monitored closely until fully recovered. A heat lamp (250W) was used to keep animals warm during recovery. Mice were monitored every $15 \mathrm{~min}$ for the remainder of the day following anesthesia.

\section{Post-tick attachment}

The bedding under each mouse cage was replaced with a plastic tub which was filled with $\sim 1.5-\mathrm{cm}$ of water (moat) (Fig. 3). The purpose of the moat was to collect replete larvae and prevent larvae from escaping. Metal brackets were positioned under each cage, serving as a base to keep the entire cage suspended above the water. Petroleum jelly was applied to the walls of the moat as an additional barrier to prevent larvae from escaping. At Day 2 post-tick attachment, mice were again anesthetized using the previously described method and the capsule lids were permanently removed in an effort to (i) observe larvae within the capsule during attachment and feeding, and (ii) allow larvae to exit the capsules after feeding to repletion and detaching.

The post-tick attachment period was commenced at Day 1 (TDay1, CDay1), Day 9 (TDay9, CD-9), and Day
15 (TDay15, CDay15) post-exposure. The day larvae were placed into capsules was defined as Day 0 posttick attachment. After applying larvae to capsules on Day 0, larvae remained on the mice and were monitored continuously over the next 4 consecutive days (Day 1 to Day 4 post-tick attachment).

During post-tick attachment, two methods of observing larvae were used: (i) collecting unfed or replete larvae from moats; and (ii) observing attached larvae within the capsules via microscopy. These methods were used to determine if fipronil bait prevented larvae from feeding to repletion and detaching from the host.

i. Immediately following tick attachment, each moat was scanned for larvae twice daily, and the status of each larva (unfed or replete) was recorded. After each scan was completed, and after all observable larvae were collected, the water within each moat was replaced. Replete larvae recovered during scans were engorged and black, resembling poppyseeds when observed with the naked eye [25], and typically floated on the surface of the water. A comparison of replete and unfed larvae can be seen in Fig. 4. Replete larvae were removed from the moats, washed thoroughly with distilled water, and allowed to dry on filter paper $(7.0 \mathrm{~cm})$. Unfed larvae removed from moats were placed into $90 \%$ ethanol and disposed of. Unfed larvae collected from moats were not included in efficacy estimates. Sanitized replete larvae were then placed into sample tubes and maintained in a desiccator under the same conditions previously described.
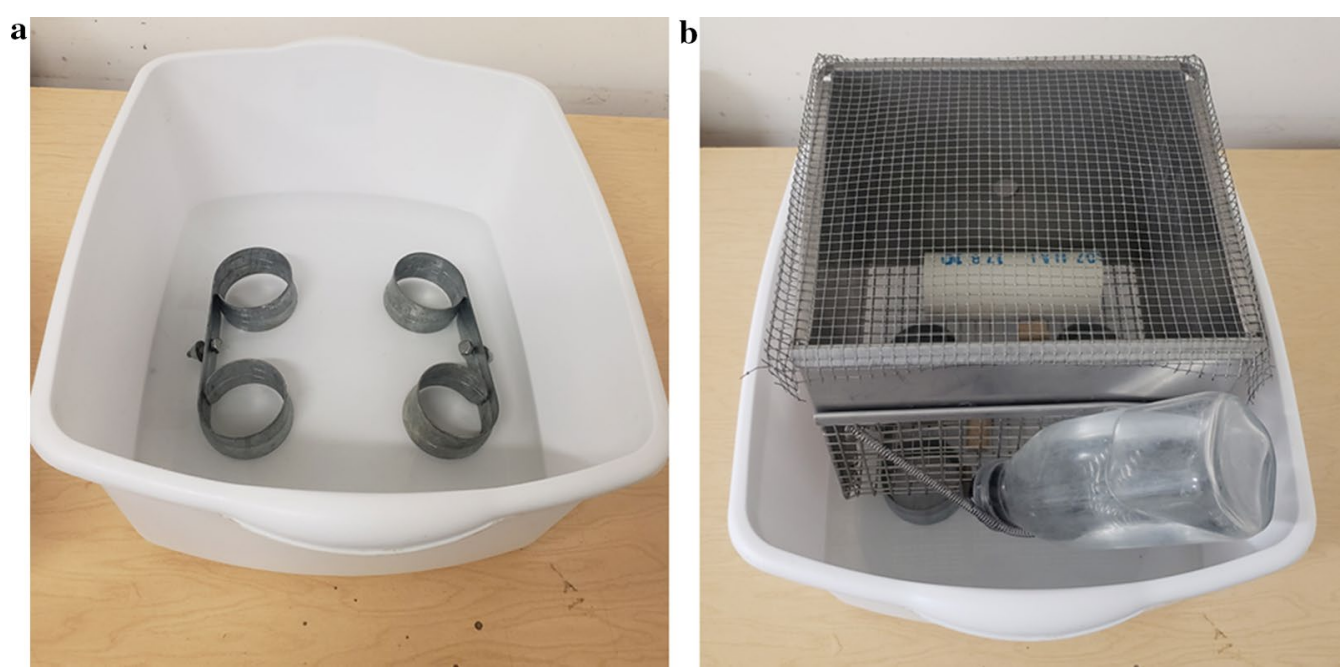

Fig. 3 Cage and moat used during post-tick attachment. a moat with $\sim 1.5 \mathrm{~cm}$ water and brackets used to suspend cage. The walls of the tubs were coated with petroleum jelly. b Cage, with food, water, and polyvinyl chloride (PVC) shelter, positioned within the moat 


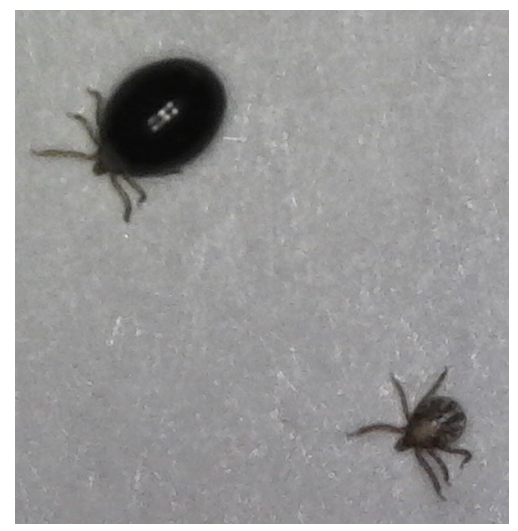

Fig. 4 Comparison of unfed larvae (bottom) and replete larvae (top)

ii. At Day 2 (48-h) and Day 4 (96-h) post-tick attachment, each mouse was anesthetized using the previously described methods and placed individually under a microscope $(2-4 \times)$ to observe the inside of the capsule. The inside of the capsule was carefully scanned for any observable, attached larvae. Attached larvae were those that were imbedded in the skin of the mice and attempting/having attempted to blood-feed. Attached larvae were examined closely and identified as non-engorged (flat or desiccated) or engorging (actively feeding and swollen). After identifying all observable larvae, representative images of the inside of the capsules were taken using a digital microscope (Plugable Technologies, Redmond, WA, US) connected to a portable laptop computer. The adhesive properties of the mixture were robust, with 59 of 60 capsules (98.3\%) remaining on test mice throughout post-tick attachment. Capsules were carefully removed from mice at the conclusion of microscope observations on Day 4 post-tick attachment. To prevent pain and distress, capsules were slowly and gently removed while mice were anesthetized. Mice were then returned to holding.

An explicit schedule detailing the dates of acclimation, exposure, post-exposure, tick attachment, and post-Tick Attachment for each test group is presented in Additional file 1 .

\section{Fipronil plasma concentration}

Sixteen mice were selected for blood collection requiring euthanasia, to determine the fipronil concentration in plasma (CP). Mice were selected using a sequence generator (random.org). Mice were anesthetized in the same manner as described previously and euthanized using cervical dislocation in accordance with the United States Animal Welfare Act (AWA) recommended procedures [40]. Approximately $100 \mu \mathrm{l}$ blood was collected from each animal via cardiac puncture using a 1cc syringe with 28-gauge needle. Blood samples were placed in a centrifuge and spun at $6100 \times \mathrm{rpm}$ for $10 \mathrm{~min}$.

Plasma was collected from mice selected from TDay 9 $(n=4)$ and TDay15 $(n=4)$, at the conclusion of the respective post-tick attachment periods (Days 13 and 19 post-exposure). To obtain Day $1 \mathrm{CP}, 4$ extra-mice were exposed to fipronil bait for $48 \mathrm{~h}$ and plasma was collected at 24-h post-exposure. Hence, the 4 extra-mice were not utilized during the tick attachment or post-tick attachment period. Finally, 4 control mice were randomly selected for plasma collection. Plasma samples were stored at $-20{ }^{\circ} \mathrm{C}$ until analysis was conducted. Plasma samples were analyzed for CP of fipronil and fipronil metabolites $(\mathrm{ng} / \mathrm{ml})$ using a validated liquid chromatography-mass spectrometry (LC/MS) procedure with a limit of quantification (LOQ) of $1.25 \mathrm{ng} / \mathrm{ml}$.

\section{Data analyses \\ White-footed mouse body weights}

Body weights of all mice were recorded prior to fipronil bait exposure and at study termination. Differences in body weight between test groups (treatment $v s$ control) and within each test group (initial weight $v s$ final weight) were estimated using a Student's t-test $(P \leq 0.05)$.

\section{Fipronil bait consumption}

Fipronil bait consumption was weighed daily for each mouse. We then estimated the total fipronil consumed by each mouse each day. The body weights taken prior to fipronil bait exposure were used to estimate total fipronil consumption in $\mathrm{mg} / \mathrm{kg}$ for each mouse. Differences in fipronil consumption $(\mathrm{mg} / \mathrm{kg}$ ) between groups were estimated using a single-factor one-way analysis of variance (ANOVA; $P \leq 0.05$ ). Differences in daily fipronil consumption $(\mathrm{mg} / \mathrm{kg})$ recorded at Day 1 (24-h) and Day 2 (48-h) post-exposure, were estimated using a Student's t-test $(P \leq 0.05)$.

\section{Tick observations}

All larvae detaching from mice were collected from moats, and the total number and status of the larvae (unfed, replete) were recorded daily during the post-tick attachment period. Larvae within capsules were observed under the microscope and were counted and their status (non-engorged, engorging) determined at Day 2 and Day 4 post-tick attachment. Observed larvae were defined as: Unfed: flat larvae, showing no discernable blood meal, collected from moats; Replete: engorged, darkly colored larvae collected from moats; Non-engorged: attached larvae, 
which expired and desiccated and/or had no discernible blood meal, observed via microscopy; Engorging: attached, actively feeding, bloated larvae observed via microscopy.

\section{Repletion efficacy}

Efficacy of fipronil bait against larvae was evaluated in two ways: (i) whether it reduced the number of replete larvae collected in the moats; and (ii) whether it prevented larvae observable under the microscope from successfully detaching from the host. The rate of immature tick attachment is often low [30] and therefore the efficacy of fipronil bait in preventing larvae from feeding to repletion was calculated using the following equation described by Henderson \& Tilton [41] to adjust efficacy to account for a loss of larvae within the control groups:

$$
\operatorname{Efficacy}(\%)=100 \times\left(1-\frac{T a \times C b}{T b \times C a}\right)
$$

where $T$ is the treatment group, $C$ is the control group, $b$ is the mean initial number of larvae placed into capsule per mouse, and $a$ is the mean number of replete larvae collected per mouse.

\section{Attachment efficacy}

The post-tick attachment microscope observations were used to estimate the number of larvae within capsules successfully detaching from mice. The total larvae successfully detaching from each mouse was estimated using the following formula:

Total successfully detached $=$ Total attached (Day 2) Total attached (Day 4)

The efficacy of the TS in preventing larvae from successfully detaching was calculated using the Henderson \& Tilton equation [41], with the variables redefined as follows: $T$, treatment group; $C$, control group, $b$, total attached (Day 2); $a$, total successfully detached.

Differences in the number of (i) replete larvae collected from moats per test group; (ii) attached non-engorged and engorging larvae within capsules per test group; and (iii) larvae within capsules successfully detaching per test group, were analyzed using a Wilcoxon signed-rank test $(P<0.05)$. All statistical analyses were performed using JMP Statistical Software (Version 15) (Cary, NC, US).

\section{Good Laboratory Practice standards}

This study was conducted according to EPA (1998) Good Laboratory Practice Standards (GLP) which are required for Federal Insecticide, Fungicide, and Rodenticide Act (FIFRA) pesticide registration (Title 40. Protection of Environment, Code of Federal Regulations Part 160 Good Laboratory Practice Standards). As per GLP requirements, an independent quality assurance unit monitored and inspected all components of the study.

\section{Results}

\section{Body weights}

The mean initial and final body weights for test groups are presented in Table 2. On average, each test group weight increased at the final weight relative to initial weight, with only females in CDay9 decreasing on average. Initial (Student's t-test: $t_{(44)}=-0.949, P=0.347$ ) and final (Student's t-test: $t_{(44)}=0.849, P=0.400$ ) body weights did not differ significantly when comparing treatment and control groups and no groups demonstrated significant weight loss over the course of the study. The final weight of treatment groups was significantly greater than the initial weight (Student's t-test: $t_{(44)}=-3.286$, $P=0.002$ ).

\section{Fipronil bait consumption}

Fipronil consumption was similar when (i) comparing Day 1 and Day 2 consumption, and (ii) comparing consumption between the three treatment groups. Fipronil consumption $(\mathrm{mg} / \mathrm{kg})$ did not differ significantly at Day 1 and Day 2 exposure (Student's t-test: $t_{(44)}=0.094$, $P=0.926)$ and did not differ significantly between TDay1, TDay9, and TDay15 mice (ANOVA: $F_{(3,27)}=0.910$, $P=0.408$ ). Total fipronil bait consumption averaged between $6.0 \mathrm{~g}$ and $6.9 \mathrm{~g}$ for treatment group mice (Table 3).

\section{Repletion of tick larvae}

Fipronil bait had a significant impact on the number of replete larvae collected from moats at all timepoints post-exposure. Within all three treatment groups, fipronil bait resulted in efficacy of $100 \%$ with 0 replete larvae being collected from moats (Table 4). The numbers of replete larvae collected within moats in each treatment group, relative to each control group, were

Table 2 Initial and final bodyweights (g) for white-footed mice within each test group (Mean \pm SD)

\begin{tabular}{llll}
\hline Test Group & Sex & Initial weight $(\mathrm{g})$ & Final weight $(\mathrm{g})$ \\
\hline CDay1 & Male & $20.2 \pm 1.8$ & $21.6 \pm 2.6$ \\
& Female & $17.9 \pm 1.6$ & $20.6 \pm 1.6$ \\
CDay9 & Male & $19.9 \pm 2.0$ & $20.2 \pm 2.2$ \\
& Female & $18.2 \pm 2.4$ & $17.5 \pm 3.2$ \\
CDay15 & Male & $18.6 \pm 2.5$ & $19.4 \pm 2.3$ \\
& Female & $19.6 \pm 3.7$ & $19.7 \pm 3.2$ \\
TDay1 & Male & $19.1 \pm 1.4$ & $22.4 \pm 2.7$ \\
& Female & $17.2 \pm 1.5$ & $19.5 \pm 1.1$ \\
TDay9 & Male & $18.7 \pm 1.0$ & $19.7 \pm 1.4$ \\
& Female & $17.3 \pm 1.4$ & $19.7 \pm 2.4$ \\
TDay15 & Male & $20.2 \pm 2.5$ & $20.2 \pm 2.0$ \\
& Female & $18.2 \pm 3.2$ & $20.8 \pm 1.8$ \\
\hline
\end{tabular}


Table 3 Fipronil bait consumption by treatment group mice $(n=30)$ (Mean \pm SD)

\begin{tabular}{|c|c|c|c|c|c|}
\hline \multirow[t]{2}{*}{ Treatment group } & \multirow[t]{2}{*}{ Sex } & \multirow[t]{2}{*}{ Body Weight (g) } & \multicolumn{3}{|c|}{ Consumption } \\
\hline & & & Bait (g) & Fipronil (mg) & $\begin{array}{l}\text { Fipronil (mg)/ } \\
\text { Body weight } \\
(\mathrm{kg})\end{array}$ \\
\hline \multirow[t]{3}{*}{ TDay1 } & Male & $19.1 \pm 1.4$ & $6.9 \pm 2.1$ & $0.35 \pm 0.10$ & $17.89 \pm 3.97$ \\
\hline & Female & $17.2 \pm 1.5$ & $6.6 \pm 1.5$ & $0.33 \pm 0.08$ & $19.03 \pm 2.82$ \\
\hline & Overall & $18.11 \pm 1.7$ & $6.8 \pm 1.8$ & $0.34 \pm 0.09$ & $18.46 \pm 3.49$ \\
\hline \multirow[t]{3}{*}{ TDay9 } & Male & $18.7 \pm 1.0$ & $6.5 \pm 0.4$ & $0.33 \pm 0.02$ & $17.47 \pm 1.28$ \\
\hline & Female & $17.3 \pm 1.4$ & $6.1 \pm 0.6$ & $0.31 \pm 0.03$ & $17.85 \pm 2.45$ \\
\hline & Overall & $18.0 \pm 1.4$ & $6.3 \pm 0.6$ & $0.32 \pm 0.03$ & $17.66 \pm 1.96$ \\
\hline \multirow[t]{3}{*}{ TDay15 } & Male & $20.2 \pm 2.5$ & $6.9 \pm 1.3$ & $0.35 \pm 0.06$ & $16.99 \pm 1.22$ \\
\hline & Female & $17.3 \pm 1.4$ & $6.0 \pm 1.0$ & $0.30 \pm 0.05$ & $16.90 \pm 4.12$ \\
\hline & Overall & $19.2 \pm 3.1$ & $6.5 \pm 1.2$ & $0.32 \pm 0.06$ & $16.94 \pm 3.04$ \\
\hline
\end{tabular}

significantly different (Wilcoxon signed-rank test: $Z=-10.103, P<0.0001)$. In the control groups (CDay1, CDay9, CDay15), a total of 502 replete larvae were collected from within the moats. Larvae did not feed to repletion until Day 3 post-tick attachment, with all replete larvae being collected at Day 3 and Day 4.

\section{Attachment and detachment of tick larvae}

Fipronil bait had a significant impact on the status of attached larvae within the capsules and the ability of these larvae to detach at all timepoints post-exposure. Within the treatment groups, at Day 2, a total of 368 larvae were observed attached within capsules of which 367 were non-engorged (99.7\%) (Wilcoxon signed-rank test: $Z=7.067, P<0.0001)$. At Day 4, within the treatment groups, all larvae observable within capsules (including the 1 Day 2 engorging larvae) were non-engorged, desiccated, and remained attached (Tables 5, 6). In the control groups (CDay1, CDay9, CDay15), a total of 368 larvae observable within the capsules were attached to mice on Day 2 post-tick attachment, of which 352 were engorging (95.7\%) (Wilcoxon signed-rank test: $Z=-6.767, P<0.0001)$. A total of 348 larvae $(94.6 \%)$ successfully detached by the end of Day 4 . The number of larvae failing to detach by Day 4 post-tick attachment was significantly greater within the treatment groups relative to control (Wilcoxon signed-rank test: $Z=-7.124$, $P<0.0001)$. Fipronil bait demonstrated $100 \%$ efficacy in preventing larvae within capsules from successfully detaching from mice (Table 6). Figure 5 presents a Day 15 post-exposure comparison of non-engorged (expired) larvae on a treatment mouse and engorging (actively feeding) larvae on a control mouse (Day 2 post-tick attachment).

\section{Fipronil plasma concentration}

Fipronil sulfone, was the only fipronil metabolite detectable above the LOQ $(1.25 \mathrm{ng} / \mathrm{ml})$. CP averaged $948.9 \pm 531.0,101.2 \pm 49.6$, and $79.4 \pm 15.6 \mathrm{ng} /$ $\mathrm{ml}$ (arithmetic mean \pm standard deviation (SD)) for

Table 4 Efficacy of fipronil bait in preventing larvae from feeding to repletion

\begin{tabular}{|c|c|c|c|c|c|}
\hline \multirow[t]{2}{*}{ Test group } & \multicolumn{2}{|c|}{ Total no. of replete larvae } & \multirow{2}{*}{$\begin{array}{l}\text { No of replete larvae } \\
\text { recovered }\end{array}$} & \multirow{2}{*}{$\begin{array}{l}\text { Mean no. of replete larvae per } \\
\text { animal } \pm S D\end{array}$} & \multirow{2}{*}{$\begin{array}{l}\text { Repletion } \\
\text { efficacy } \\
(\%)\end{array}$} \\
\hline & Day $3^{\text {ab }}$ & Day $4^{\mathrm{ab}}$ & & & \\
\hline CDay1 & 77 & 55 & 132 & $13.2 \pm 4.6$ & \\
\hline CDay9 & 92 & 90 & 182 & $18.2 \pm 4.0$ & \\
\hline CDay15 & 95 & 93 & 188 & $18.8 \pm 7.3$ & \\
\hline Control total & 264 & 238 & 502 & & \\
\hline TDay1 & 0 & 0 & 0 & 0 & 100 \\
\hline TDay9 & 0 & 0 & 0 & 0 & 100 \\
\hline TDay15 & 0 & 0 & 0 & 0 & 100 \\
\hline Treatment total & 0 & 0 & 0 & & 100 \\
\hline
\end{tabular}

\footnotetext{
a Days post-tick attachment

b No larvae fed to repletion prior to Day-3 post-tick attachment
} 
Table 5 Attached non-engorged and engorging larvae observable within the capsule under the microscope

\begin{tabular}{|c|c|c|c|c|}
\hline \multirow[t]{2}{*}{ Test group } & \multicolumn{2}{|c|}{ Day 2 (post-tick attachment) } & \multicolumn{2}{|c|}{ Day 4 (post-tick attachment) } \\
\hline & Attached non-engorged & Attached engorging & Attached non-engorged & Attached engorging \\
\hline CDay1 & $0.1 \pm 0.3$ & $9.0 \pm 1.4$ & 0 & $0.2 \pm 0.4$ \\
\hline CDay9 & $0.8 \pm 0.9$ & $12.7 \pm 3.0$ & $0.1 \pm 0.3$ & $0.2 \pm 0.4$ \\
\hline CDay15 & $0.7 \pm 0.8$ & $13.5 \pm 3.6$ & $0.2 \pm 0.4$ & $1.3 \pm 1.5$ \\
\hline TDay 1 & $10.5 \pm 2.8$ & 0 & $10.8 \pm 3.3$ & 0 \\
\hline TDay9 & $13.2 \pm 2.9$ & 0 & $13.2 \pm 2.9$ & 0 \\
\hline TDay15 & $13.0 \pm 4.0$ & $0.1 \pm 0.3$ & $13.1 \pm 4.0$ & 0 \\
\hline
\end{tabular}

Note: Number of larvae per mouse (arithmetic mean \pm SD) at Day 2 and Day 4 post-tick attachment are indicated

Table 6 The efficacy of fipronil bait in preventing successful detachment of larvae (post-tick attachment)

\begin{tabular}{|c|c|c|c|c|c|}
\hline Test group & $\begin{array}{l}\text { No. of larvae attached } \\
\text { (Day 2) }\end{array}$ & $\begin{array}{l}\text { No. of larvae attached } \\
\text { (Day 4) }\end{array}$ & $\begin{array}{l}\text { No. of larvae successfully } \\
\text { detached }\end{array}$ & $\begin{array}{l}\text { Mean no. of successfully detached } \\
\text { per mouse } \pm \text { SD }\end{array}$ & $\begin{array}{l}\text { Detachment } \\
\text { efficacy (\%) }\end{array}$ \\
\hline CDay1 & 91 & 2 & 89 & $8.9 \pm 1.4$ & \\
\hline CDay9 & 135 & 3 & 132 & $13.2 \pm 3.0$ & \\
\hline CDay15 & 142 & 15 & 127 & $12.7 \pm 2.6$ & \\
\hline TDay1 & 105 & 108 & 0 & 0 & 100 \\
\hline TDay9 & 132 & 132 & 0 & 0 & 100 \\
\hline TDay 15 & 131 & 131 & 0 & 0 & 100 \\
\hline
\end{tabular}

mice euthanized on Day 1 (TD1), Day 13 (TD9) and Day 19 (TD15) post-exposure, respectively. No fipronil was detected in control group mice. A summary of the fipronil sulfone concentrations is presented in Table 7.

\section{Discussion}

The results of this study suggest that, under laboratory conditions, a low dose fipronil bait $(0.005 \%)$, presented orally to the primary pathogen reservoir (white-footed mice) for 48 hours, can potentially control $100 \%$ of blacklegged tick larvae blood-feeding at Day 1, Day 9 and Day 15 post-exposure. These results are an early indicator of the potential use of fipronil bait for B. burgdorferi (s.s.) prevention in the midwestern and northeastern USA. Under field conditions, successfully preventing larvae from feeding to repletion would reduce the influx of infected nymphs the following spring, reducing the risk of infected tick bites. Additional research may aid in determining key factors to maximize the success of this approach while also minimizing potential risks.

Future studies should be designed to answer additional questions regarding the efficacy of fipronil bait against larvae, which would aid in development of a field trial. First, the efficacy of fipronil bait should be evaluated at additional timepoints ranging from 21-42 days postexposure. Although there were no rodenticides in the formulation used during this study, it was initially suggested that the bait be formulated with the first-generation anticoagulant warfarin at $0.025 \%$, which is considered the nominal concentration presented in most commercially available rodenticides [42]. The theory was that many end-users would elect to remove the rodents, given the role that Peromyscus spp. play in Hantavirus [43] and Lyme disease [44] transmission. The debate about the use of an acaricide/rodenticide combination formulation was centered on the argument that mass die-offs of rodent species can result in the release of arthropod vectors into the surrounding environment, presenting an increased threat to humans $[45,46]$. The post-exposure timepoints utilized during the present study span the relative days until death reported for first-generation anticoagulants, which average 5-7 days and up to 12 and 13 days for laboratory mice and rats, respectively [47]. One hundred percent (100\%) of larvae were prevented from feeding to repletion even at Day 1, Day 9 and Day 15 post-exposure, indicating the potential use of fipronil bait as an acaricide-only product. Given that $100 \%$ efficacy was obtained during this study, we were unable to calculate the $\mathrm{LD}_{50}$ of low dose fipronil bait. Considering we observed a larva within TDay15 feeding at Day 2 post-tick attachment, it is likely that efficacy would decrease at least slightly within the coming weeks. The CP level recorded at Day $19(79.4 \mathrm{ng} / \mathrm{ml})$ indicates that fipronil sulfone might persist in mice over several weeks, and therefore efficacy at additional timepoints should be evaluated. 

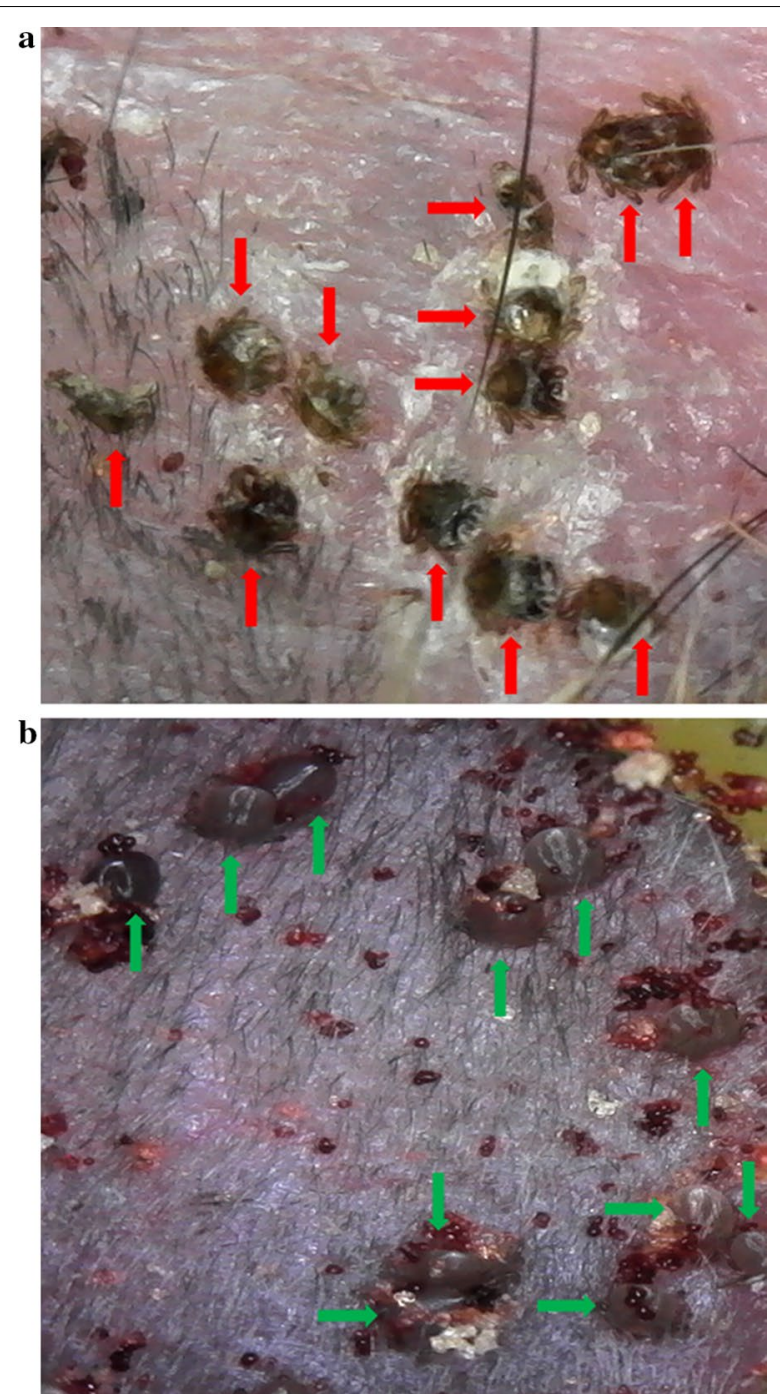

Fig. 5 Larvae attached to a mouse exposed to fipronil bait (a) and a control mouse (b). These mice had larvae attached at Day-15 post-exposure. The photos were taken at Day-2 post-tick attachment. Red arrows indicate expired, desiccated larvae and green arrows indicate larvae that are engorging. The partial engorgement and presence of red feces indicate the actively feeding larvae. Photos were taken using a digital microscope (Plugable Technologies, Redmond, WA, USA)

Future research should evaluate the efficacy of fipronil bait at variable exposure durations. As previously stated, mice were exposed to fipronil bait for 48 hours to compensate for potential neophobic reactions. However, our results indicated that neophobia may not be a significant issue as consumption did not differ significantly when comparing Day 1 and Day 2 consumption. This indicates that a mouse may be capable to consuming the necessary amount of fipronil within 24 hours to effectively control larvae, suggesting that this should be explored
Table 7 The mean ( \pm SD) consumption and CP for fipronil sulfone in 16 mice

\begin{tabular}{lll}
\hline $\begin{array}{l}\text { Plasma collection day (post- } \\
\text { exposure) }\end{array}$ & $\begin{array}{l}\text { Fipronil consumption } \\
\text { (mg/kg) }\end{array}$ & $\begin{array}{l}\text { Fipronil } \\
\text { concentration } \\
\text { (ng/ml) }\end{array}$ \\
\hline Control & 0 & 0 \\
Day 1 & $11.0 \pm 3.5$ & $948.9 \pm 531.0$ \\
Day 13 & $16.8 \pm 0.3$ & $101.2 \pm 49.6$ \\
Day 19 & $17.6 \pm 4.6$ & $79.4 \pm 15.6$ \\
\hline
\end{tabular}

explicitly during future experiments. Additionally, prior research suggests that although white-footed mice may initially exhibit a neophobic response to new stimuli, they quickly become neophiliac [48]. This suggests that, under field conditions, a mouse may return to feed on fipronil bait repeatedly over $>2$ consecutive days. If this were to occur, the $\mathrm{CP}$ in plasma of wild mice might be elevated enough for efficacy to be maintained for longer durations.

The results of the present study suggested that $0.005 \%$ fipronil bait, presented orally for 48-hours, posed minimal risk to mice. All mice remained healthy throughout the study, and no test groups exhibited weight loss. Average final weights were increased for all test groups and were significantly greater within the treatment groups. This was likely in part a byproduct of reduced stimulus, as these mice were normally group-housed in large enclosures while in holding. The significant increase in the weight of treatment mice could have additionally resulted from the removal of ectoparasites resulting from fipronil exposure. Although fipronil is considered moderately toxic when administered orally, as opposed to moderate to low toxicity when administered dermally/topically [49], the concentration of fipronil in the current bait is $19.4 \times$ and $9.7 \times$ lower than the bait utilized during prior work with fipronil [25]. The oral $\mathrm{LD}_{50}$ of fipronil for laboratory mice is $\sim 97 \mathrm{mg} / \mathrm{kg}$ body weight. Given the concentration of fipronil in the bait (0.005\%), a $20 \mathrm{~g}$ white-footed mouse would need to eat $\sim 39 \mathrm{~g}$ of bait within 24 hours in order to reach the oral $\mathrm{LD}_{50}$, an improbable feat. However, additional studies, in which mice are exposed to fipronil bait chronically, could provide useful insights.

The results suggest that targeted white-footed mouse treatment with a fipronil-based oral acaricide could be economically advantageous. The desired end-use would be for pest control professionals and homeowners to be able to utilize the fipronil bait in a species-specific bait station. Ideally, a bait station could be placed in the field and remain for several weeks, without any need for maintenance such as replacement of topical wicks, as is required with the TCS bait box. Fipronil has been found to be a particularly effective compound when used for arthropod 
control. Researchers in Wyoming suggested that fipronil could be effectively applied at rates 100-200× less than alternative compounds when applied aerially for grasshopper control [50]. These researchers further hypothesized that the ability to apply fipronil at reduced concentrations may have mitigated toxicity to non-target species. Poche et al. [34] noted the above study and compared the application rates to that of a field trial in Kazakhstan utilizing a fipronil bait containing $0.005 \%$ fipronil. This study resulted in $100 \%$ efficacy against fleas (Xenopsylla spp.) infesting great gerbils (Rhombomys opimus) up to 80 days postapplication with the bait being applied at a rate $>65 \times$ less than during the previously described study in Wyoming. Thus, specifically targeting the white-footed mouse with a fipronil bait presented in a species-specific bait station may significantly reduce the amount of labor required for the end-user and will exponentially reduce the amount of active ingredient being utilized relative to approaches such as blanket spraying. Future studies, including a large-scale field trial, could indicate the necessary application rates and provide more definitive insights into any potential economic or environmental advantages associated with this tick control approach.

Observing the larvae attached to mice via microscopy proved to be a useful addition to estimating the efficacy of fipronil bait. Larvae succumbing to fipronil remained attached to mice and therefore were not able to be collected from the water. Hence, this method allowed us to compare attached larvae within the treatment groups and control groups and confirm their condition. The results clearly demonstrate that larvae that attached to mice within the treatment groups were not able to feed to the extent that larvae attaching to mice within the control groups were and expired prior to reaching repletion and detaching. Although this method improved our ability to observe attached larvae, the number of replete larvae collected within moats was greater than the number observed under the microscope, indicating that a number of larvae attached to mice were not observable. Overall, this method proved useful in confirming the effectiveness of a systemic fipronil bait in controlling bloodfeeding larvae. It should be noted that while the feeding capsules localized the larval feeding and prevented some larvae from escaping, a significant proportion $(44.9 \%)$ of larvae were still never recovered. That is why the equation described by Henderson and Tilton [41] was utilized, allowing us to consider the loss of larvae within the control groups. Larvae were lost for several reasons such as escaping at the base of the capsules under mouse fur. While unfed larvae were recovered in the water moats, many specimens were never found. It was assumed that some larvae attached to feces or other debris in moats and were not found during scans. The difficulties associated with tick feeding have been described in previous studies $[26,30,51]$. Larvae are particularly challenging to recover because of their small size $(\leq 0.8 \mathrm{~mm}$ in length). Future studies should consider creative modifications to further improve tick attachment and recovery under laboratory conditions.

As was the case during the fluralaner studies conducted by Pelletier et al. [26], in the present study the CP of fipronil for mice was highly variable, particularly at Day 1 post-exposure. The mean CP of fipronil was markedly lower at Day 1 post-exposure $(948.9 \mathrm{ng} / \mathrm{ml})$ when compared with the mean $\mathrm{CP}$ of fluralaner at Day 2 post exposure $(0.005 \%=13,815 \mathrm{ng} / \mathrm{ml} ; 0.0 .00125 \%=4594 \mathrm{ng} /$ $\mathrm{ml}$ ); however, we should note that consumption by the Day-1 mice was low relative to the TDay9- and TDay15 mice. The $\mathrm{CP}$ of fluralaner dropped considerably at Day $28(0.005 \%=579 \mathrm{ng} / \mathrm{ml} ; 0.00125 \%=208 \mathrm{ng} / \mathrm{ml})$ and Day $42(0.005 \%=46.7 \mathrm{ng} / \mathrm{ml} ; 0.00125 \%=52 \mathrm{ng} / \mathrm{ml})$ postexposure and these researchers observed no significant effect of treatment on feeding larvae at either of these timepoints [26]. In the present study, CP of fipronil sulfone dropped to $101.2 \mathrm{ng} / \mathrm{ml}$ (Day 13) and $79.4 \mathrm{ng} /$ $\mathrm{ml}$ (Day 19). One hundred percent (100\%) efficacy was obtained at Day 9 and Day 15 post-exposure, suggesting that fipronil bait effectively controlled larvae at $\mathrm{CP}<101.2$ $\mathrm{ng} / \mathrm{ml}$. The presence of fipronil sulfone in Day-19 plasma further suggests the need to determine efficacy and $\mathrm{CP}$ at additional timepoints post-exposure (Day 21 to Day 42) to estimate the lowest quantifiable $\mathrm{CP}$ at which significant larval efficacy can still be obtained.

The potential for fipronil bait to control blacklegged tick nymphs should also be investigated. Nymphs are primarily responsible for human Lyme disease transmission and will occasionally feed on small mammals, including white-footed mice [17-20]. Significantly reducing the number of nymphs could reduce the number of adult ticks capable of feeding on relevant reproductive hosts (i.e. Odocoileus spp. deer) and reduce the B. burdorferi transmission rate from nymphs to mice. However, considering the somewhat indiscriminate feeding behavior of nymphs, this would likely require integrated vector management, perhaps utilizing the current approach in conjunction with an oral acaricide to be administered to deer (Odocoileus spp.) [52]. Future researchers might consider investigating fipronil as a means of controlling nymphal and/or adult ticks feeding on deer. Additionally, researchers should consider evaluating the use of the current fipronil bait in controlling immature ticks attached to other potential mammalian hosts such as chipmunks. Controlling nymphs, larvae and adults simultaneously could potentially disrupt multiple blacklegged tick life stages, which would provide additional tick bite protection to humans and white-footed mice. 


\section{Conclusions}

Low dose fipronil bait, administered orally to whitefooted mice for 48 hours, was efficacious in controlling blacklegged tick larvae attached to mice at Day 1, Day 9 and Day 15 post-exposure. Specifically, it was 100\% efficacious in reducing replete larvae collected from moats and preventing larvae observed within capsules from detaching. This exceeds the efficacy requirement of $90 \%$ outlined by the EPA (OPPTS 810.3300) and suggests fipronil bait could eventually become a federally registered product to be utilized as a method of reducing tick abundance. To our knowledge, this is the first study to evaluate the efficacy of oral fipronil baits, presented to the primary B. burgdorferi (s.s.) reservoir (white-footed mice), against the blood-feeding primary B. burgdorferi (s.s.) vector (blacklegged tick). Explicit data regarding the level of efficacy and CP at various durations of exposure and timepoints post-exposure should continue to be collected and evaluated. These data would provide proper insights needed to develop a field trial or management plan. Given the efficacy that fipronil rodent baits have demonstrated against ticks, fleas and phlebotomine sand flies, a low dose fipronil bait, specifically targeting ticks infesting white-footed mice, could broadly target a variety of vector-host relationships, potential reducing transmission of a diverse group of zoonotic pathogens.

\section{Supplementary information}

Supplementary information accompanies this paper at https://doi. org/10.1186/s13071-020-04258-0.

Additional file 1: Table S1. Study schedule providing the specific timing of acclimation, exposure, post-exposure, tick attachment, and post-tick attachment for each test group.

\section{Acknowledgments}

We would like to thank Dr Lars Eisen and Nicole Breuner of the United States Centers for Disease Control and Prevention (Division of Vector Borne Diseases) for providing valuable insights regarding tick application and rearing. We also thank Dr Gregory Dooley of Colorado State University (Analytical Toxicology Laboratory) for assisting in analyzing plasma via LQ/MS. Finally, we would like to thank Scimetrics Limited Corp. (Wellington, $\mathrm{CO}$ ) for manufacturing and supplying all of the fipronil bait utilized during this study. The study was greatly improved by their generosity and helpful suggestions.

\section{Authors' contributions}

DMP and RMP designed the study. DMP wrote the protocol. RMP, LP and BPT reviewed the protocol. DMP served as study team leader and director. DMP, BT and GF obtained ethical approval for animal use. DMP, GF and TC conducted the experiment. LP developed methodology for and performed all analytical chemistry procedures. DMP, GF, TC and BT organized and verified the accuracy of all raw data. DMP performed all data analyses and wrote the manuscript. DMP and RMP revised the manuscript. All authors read and approved the final manuscript.

\section{Funding}

The research described received no funding.

\section{Availability of data and materials}

Data supporting the conclusions of this article are included within the article and its additional files. The datasets generated during and/or analyzed during the present study are available from the corresponding author upon reasonable request.

\section{Ethics approval and consent to participate}

The test protocol and all procedures performed during this study involving white-footed mice were approved by the Genesis Institutional Animal Care and Use Committee (IACUC) (March 18, 2019) and followed United States Animal Welfare Act and Genesis IACUC policies (Study No. 19001).

\section{Consent for publication}

Not applicable.

\section{Competing interests}

The authors declare that they have no competing interests.

Received: 9 April 2020 Accepted: 23 July 2020

Published online: 31 July 2020

\section{References}

1. Bacon RM, Kugeler KJ, Mead PS. Surveillance for Lyme disease-United States, 1992-2006. MMWR Surveil Summ. 2008;57:1-9.

2. Beard CB., Eisen RJ, Barker CM, Garofalo JF, Hahn M, Hayden M, et al. Chapter 5: Vector-borne Diseases. In: The impacts of Climate Change on Human Health in the United States: A Scientific Assessment. Washington, DC: US Global Change Research Program; 2016. p. 132-137.

3. Centers for Disease Control and Prevention.https://wwwnc.cdc.gov/eid/ article/11/7/04-1355_article

4. Mead PS. Epidemiology of Lyme disease. Infect Dis Clin North Am. 2015;29:187-210.

5. Bunikis J, Barbour AG. Third Borrelia species in white-footed mice. Emerg Infect Dis. 2005;11:1150-1. https://doi.org/10.3201/eid1107.041355.

6. Nicholson W, Sonenshine D, Lane R, Uilenberg G. Chapter 26: Ticks (Ixodida). In: Mullen GR, Durden LA, editors. Medical and veterinary entomology. Amsterdam: Elsevier, Inc.; 2009. p. 483-532.

7. Dumler JS. Molecular diagnosis of Lyme disease: review and meta-analysis. Mol Diagn. 2001;6:1-11.

8. CDC. Tickborne Disease of the United States. Ft. Collins, CO: United States Centers for Disease Control and Prevention; 2019. https://www.cdc.gov/ ticks/diseases/index.html. Accessed 10 Feb 2020.

9. Adrion ER, Aucott J, Lemke KW, Weiner JP. Health care costs, utilization and patterns of care following Lyme disease. PLOS ONE. 2015;10:e0116767.

10. Ginsberg HS. Lyme disease and conservation. Conserv Biol. 1994;8:343-53.

11. Schulze TL, Jordan RA, Hung RW, Krivenko AJ, Schulze JJ, Jordan TM. Effects of an application of granular carbaryl on nontarget forest floor arthropods. J Econ Entomol. 2001;94:123-8.

12. Barnard DR, Jones BG, Rogers GD, Mount GA. Acaricide susceptibility in the lone star tick: assay techniques and baseline data. J Econ Entomol. 1981;74:466-9.

13. Maupin GO, Piesman J. Acaricide susceptibility of immature Ixodes scapularis (Acari: Ixodidae) as determined by the disposable pipet method. J Med Entomol. 1994;31:319-21.

14. Panella NA, Karchesy J, Maupin GO, Malan JC, Piesman J. Susceptibility of immature Ixodes scapularis (Acari: Ixodidae) to plant-derived acaricides. J Med Entomol. 1997;34:340-5.

15. Mayo Clinic Staff. Lyme Disease: Risk Factors. The Mayo Clinic; 2017. http://www.mayoclinic.org/diseases-conditions/lyme-disease/basics/riskfactors/con-20019701. Accessed 3 Feb 2020.

16. United States Centers for Disease Control and Prevention. How ticks spread disease; 2019. https://www.cdc.gov/ticks/life_cycle_and_hosts .html. Accessed 14 Feb 2020.

17. Stafford KC III, Ward JS, Magnarelli LA. Impact of controlled burns on the abundance of Ixodes scapularis (Acari: Ixodidae). J Med Entomol. 1998;35:510-3. 
18. Mather TN. The dynamics of spirochete transmission between ticks and vertebrates. In: Ginsberg HS, editor. Ecology and environmental management of Lyme disease. New Brunswick: Rutgers University Press; 1993. p. 43-62.

19. Fish D. Population ecology of Ixodes dammini. In: Ginsberg HS, editor. Ecology and environmental management of Lyme disease. New Brunswick: Rutgers University Press; 1993. p. 25-42.

20. Caraco T, Gardner G, Maniatty W, Deelman E, Szymanski BK. Lyme disease: self-regulation and pathogen invasion. J Theor Biol. 1998;193:561-75.

21. Raymond-Delpech V, Matsuda K, Sattelle BM, Rauh JJ, Sattelle DB. Ion channels: molecular targets of neuroactive insecticides. Invert Neurosci. 2005;5:119-33.

22. Dolan MC, Maupin GO, Schneider BS, Denatale C, Hamon N, Cole C, et al. Control of immature Ixodes scapularis (Acari: Ixodidae) on rodent reservoirs of Borrelia burgdorferi in a residential community of southeastern Connecticut. J Med Entomol. 2004;41:1043-54.

23. Schulze TL, Jordan RA, Williams M, Dolan MC. Evaluation of the SELECT tick control system (TCS), a host-targeted bait box, to reduce exposure to Ixodes scapularis (Acari: Ixodidae) in a Lyme disease endemic area of New Jersey. J Med Entomol. 2017;54:1019-24.

24. Williams SC, Little EA, Stafford KC III, Molaei G, Linske MA. Integrated control of juvenile Ixodes scapularis parasitizing Peromyscus leucopus in residential settings in Connecticut, United States. Ticks Tick Borne Dis. 2018;9:1310-6.

25. Borchert J, Poche RM. Novel Pest Control Methods. 2011. U.S. Patent No. US20060057178A1. https://patents.google.com/patent/US20060057 178A1/en. Accessed 17 July 2020.

26. Pelletier J, Rocheleau JP, Aenishaenslin C, Beaudry F, Masson GD, Lindsay $L R$, et al. Evaluation of fluralaner as an oral acaricide to reduce tick infestation in a wild rodent reservoir of Lyme disease. Parasit Vectors. 2020;13:73.

27. Piesman J, Eisen L. Prevention of tick-borne diseases. Annu Rev Entomol. 2008;53:323-43.

28. Levin ML, Schumacher L, Thangamani S. Laboratory colonies of ticks. Vector Biology Research Workshop. National Institutes of Health; 2015. https ://www.beiresources.org/Portals/2NectorResources/Methods\%20in\%20 Tick\%20Research.pdf. Accessed 3 Feb 2020.

29. Thangamani S, Bente D. Establishing protocols for tick containment at Biosafety Level 4. Pathog Dis. 2014;71:280-3.

30. Nuss AB, Mathew MG, Gulia-Nuss M. Rearing Ixodes scapularis, the blacklegged tick: feeding immature stages on mice. JoVE. 2017;123:e55286.

31. Sonenshine DE. Maintenance of ticks in the laboratory. Maintenance of human, animal, and plant pathogen vectors. Enfield: Science Publishers; 1999. p. 57-82.

32. Levin ML, Fish D. Density-dependent factors regulating feeding success of Ixodes scapularis larvae (Acari: Ixodidae). J Parasitol. 1998;84:36-43.

33. Poché DM, Hartman D, Polyakova L, Poché RM. Efficacy of a fipronil bait in reducing the number of fleas (Oropsylla spp.) infesting wild black-tailed prairie dogs. J Vector Ecol. 2017;42:171-7.

34. Poche DM, Torres-Poche Z, Yeszhanov A, Poche RM, Belyaev A, Dvořák V, Sayakova Z, Polyakova L, Aimakhanov B. Field evaluation of a $0.005 \%$ fipronil bait, orally administered to Rhombomys opimus, for control of fleas (Siphonaptera: Pulicidae) and phlebotomine sand flies (Diptera: Psychodidae) in the Central Asian Republic of Kazakhstan. PLoS Neglect Trop Dis. 2018;12:e0006630.

35. Ingenloff K, Garlapati R, Poché D, Singh MI, Remmers J, Poché RM. Feed-through insecticides for the control of the sand fly Phlebotomus argentipes. Med Vet Entomol. 2013;27:10-8.

36. Kocan KM, de la Fuente J, Coburn LA. Insights into the development of Ixodes scapularis: a resource for research on a medically important tick species. Parasit Vectors. 2015;8:592.

37. United States Environmental Protection Agency (EPA). OPPTS 810.3300: Treatments to Control Pests of Humans and Pets. Washington, DC: EPA; 1998. https://nepis.epa.gov/Exe/ZyNET.exe/ P100IJCA.TXT?ZyActionD=ZyDocument\&Client=EPA\&Index $=1995+$ Thru+1999\&Docs=\&Query=\&Time=\&EndTime=\&SearchMeth $\mathrm{od}=1 \&$ TocRestrict $=$ n\&Toc $=\&$ TocEntry $=\&$ QField $=\&$ QField Year $=\&$ QFiel $\mathrm{dMonth}=\& Q$ FieldDay $=\&$ IntQField $\mathrm{O} p=0 \&$ ExtQFieldOp $=0 \& \mathrm{Xm|Qu}$ ery $=\&$ File $=$ D\%3A\%5Czyfiles\%5CIndex\%20Data\%5C95thru99\%5CTxt \%5C00000034\%5CP100IJCA.txt\&User=ANONYMOUS\&Password=anony mous\&SortMethod=h\%7C-\&MaximumDocuments=1\&Fuzzy Degree $=0 \&$ ImageQuality $=$ r75g8/r75g8/x150y150g16/i425\&Displ $a y=h p f r \&$ DefSeekPage $=x \&$ SearchBack $=$ ZyActionL\&Back=ZyAct ionS\&BackDesc $=$ Results\%20page\&MaximumPages = 1\&ZyEnt $r y=1 \&$ SeekPage $=x \& Z y$ PURL. Accessed 10 Feb 2020.

38. United States Environmental Protection Agency (EPA). OPP Designation 1.216: Standard Peromyscus species anticoagulant dry bait laboratory testing method; 1991. https://www.epa.gov/sites/production/files/202002/documents/1-216pand.pdf. Accessed: 10 Feb 2020.

39. Greggor AL, Thornton A, Clayton NS. Neophobia is not only avoidance: improving neophobia tests by combining cognition and ecology. Curr Opin Behav Sci. 2015;6:82-9.

40. Leary S, Underwood W, Anthony R, Cartner S, Corey D, Grandin T, et al. AVMA Guidelines for the Euthanasia of Animals. Schaumburg: American Veterinary Medical Association; 2013.

41. Henderson CF, Tilton EW. Tests with acaricides against the Brown Wheat Mite. J Econ Entomol. 1955;48:157-61.

42. United States Environmental Protection Agency (EPA). Reregistration Eligibility Document: Warfarin and its sodium salt. Washington, DC: Office of Pesticide Programs, Special Review and Reregistration Division; 1991. https://www.epa.gov/nscep. Accessed 19 Mar 2020.

43. Childs JE, Ksiazek TG, Spiropoulou CF, Krebs JW, Morzunov S, Maupin GO, et al. Serologic and genetic identification of Peromyscus maniculatus as the primary rodent reservoir for a new hantavirus in the southwestern United States. J Infect Dis. 1994;169:1271-80.

44. Schwan TG, Kime KK, Schrumpf ME, Coe JE, Simpson WJ. Antibody response in white-footed mice (Peromyscus leucopus) experimentally infected with the Lyme disease spirochete (Borrelia burgdorferi). Infect Immun. 1989;57:3445-51.

45. Clark J.P. Vertebrate Pest Control Handbook: 4th edition. 1994. Sacramento, CA: California Department of Food and Agriculture.

46. Borchert JN, Davis RM, Poché RM. Field efficacy of rodent bait containing the systemic insecticide imidacloprid against the fleas of California ground squirrels. J Vector Ecol. 2009;34:92-8.

47. Poché RM, Poché DM. Rodenticides: warfarin, still a good management tool. Outlooks Pest Manag. 2012;23:132-5.

48. Sheppe W. Exploration by the deer mouse. Peromyscus leucopus. Am Midl Nat. 1966;1:257-76.

49. EPA. New Pesticide Fact Sheet: Fipronil. 1996. https://nepis.epa.gov/. Accessed 19 Mar 2020.

50. Norelius EE, Lockwood JA. The effects of reduced agent-area insecticide treatments for rangeland grasshopper (Orthoptera: Acrididae) control on bird densities. Arch Environ Contam Toxicol. 1999;37:519-28.

51. Nilsson A, Lundqvist L. Host selection and movements of Ixodes ricinus (Acari) larvae on small mammals. Oikos. 1978;1:313-22.

52. Rand PW, Lacombe EH, Holman MS, Lubelczyk C, Smith RP Jr. Attempt to control ticks (Acari: Ixodidae) on deer on an isolated island using ivermectin-treated corn. J Med Entomol. 2000;37:126-33.

\section{Publisher's Note}

Springer Nature remains neutral with regard to jurisdictional claims in published maps and institutional affiliations.

\footnotetext{
Ready to submit your research? Choose BMC and benefit from:

- fast, convenient online submission

- thorough peer review by experienced researchers in your field

- rapid publication on acceptance

- support for research data, including large and complex data types

- gold Open Access which fosters wider collaboration and increased citations

- maximum visibility for your research: over $100 \mathrm{M}$ website views per year
}

At BMC, research is always in progress.

Learn more biomedcentral.com/submissions 